\title{
Introduction to a new order, traceability and inventory online program for medical practices
}

\section{Introduction}

All dental clinics are facing the same issues related to items orders, traceability, inventory, real time evaluation of the inventory, expire dates management, price of same items sold by different distributors, medico-legal constraints, consumption evaluation of all Items or of some dedicated items, export of payment details to accountancy, etc.

An excel file or an accountancy program are by far not enough to answer to all these issues. Easy Stock-in ${ }^{1}$ has been designed to simplify this management in real time.

This paper is a short introduction to Easy Stock-in software.

1. It is not necessary to install the software on a computer, all is accessible online.

2. It is not needed to make back up. Your data are stored on a Server in Europe and back up are done every 10 minutes.

3. You can access to your data from everywhere in the world as long as you are connected to the Internet.

4. You can use any computer or any tablet.

5. You can use any currency

\section{Structure of the Program}

Easy Stock-in is set up with 4 types of buttons with a different color: blue for the Everyday practice, yellow for the reports, orange for the customized reports and green for your settings.

\section{Everyday practice (in Blue) (Figure I)}

Everyday practice

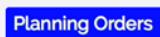

Sent Orders Management

\section{Inventory \& Traceability}

Add Items without placing order

Figure I Everyday practice.

\section{Planning Orders}

Volume 4 Issue 2 - 2016

\author{
Philippe Tardieu \\ Private practitioner in Dubai, UAE
}

Correspondence: Philippe Tardieu, Private practitioner in Dubai, UAE, Email pt@frenchdentistdubai.com

Received: June 16, 2015 | Published: February 15, 2016

\section{Planning orders}

In Planning Orders, you can check the contents of each Lot. For example a Lot is equal to "1 box of masks"; one line will be edited for one box of 50 masks. The number of items in inventory at the time of ordering is automatically displayed. This will avoid orders Items which are already in stock somewhere (Figure 2).

\section{Sent orders management}

In the details of Sent Orders Managements, the date of delivery, the amount of the invoice and the details of payments allow following your order from A to $\mathrm{Z}$.

A customized report allows send this information to the accountancy. A field automatically shows how many days you have in between the date of order and today or the date of order and the date of delivery.

\section{Basket}

This tool allows setting up the list of all used Items for an intervention with the details of prices and the total amount. This is interesting to do if you want to separate the honorarium from the amount of used items during an intervention. It is also used to evaluate the amount of components used to fabricate prosthesis for example (Figure 3).

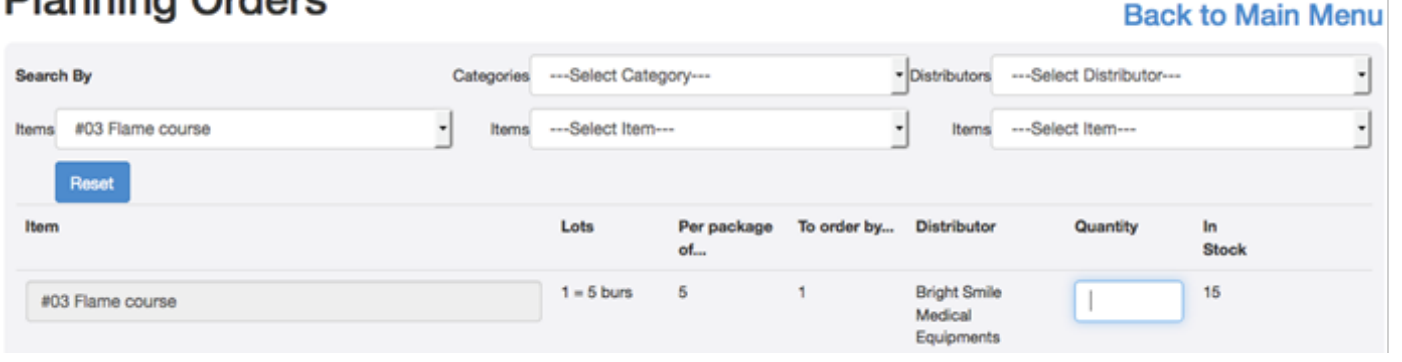

Figure 2 Planning orders.

${ }^{1}$ Easy Stock-in web page: http://www.anpamedical.com/informations/easy-stock-in 


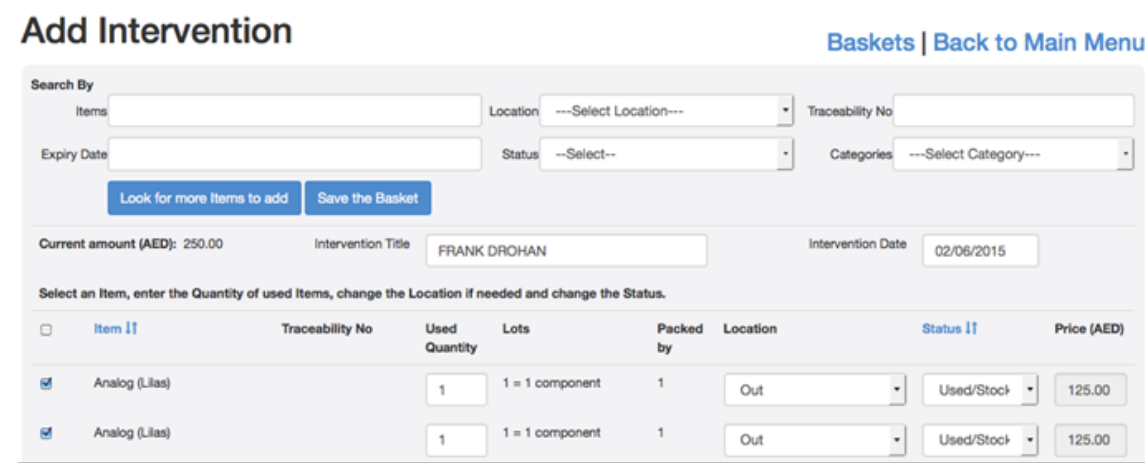

Figure 3 Add intervention.

The Basket is done in such a way that you can select one or several items included in a basic package (for example 6 gloves have been used out of a box of 50 gloves). And the price will be automatically calculated.

\section{Stock and traceability}

The background of the expired Items is displayed in red color to avoid mistakes (Figure 4).

\begin{tabular}{|c|c|c|c|c|c|c|c|c|}
\hline 曰 & Item It & Location It & & Traceability No It & Expiry Date It & Status If & & Comment It \\
\hline $\boldsymbol{e}$ & $\begin{array}{l}\text { Master-C conical implant - } 63.50 \mathrm{~mm}-\mathrm{L}= \\
11.5 \mathrm{~mm}\end{array}$ & -.Select- & $\cdot$ & & $01 / 06 / 2015$ & Received & ${ }^{\circ}$ & \\
\hline 曰 & Fiber Force CST Pillars for laboratory & --Select-- & $\cdot$ & & & Received & 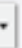 & ()ㅜ \\
\hline
\end{tabular}

Figure 4 Stock and traceability.

\section{Reports (in Yellow) (Figure 5)}

\section{Reports \\ Today's Inventory \\ Expired in-stock Items \\ Quick Inventory \\ Dynamic Inventory Report}

Todays in-use Items

Expired in-use Items

One month Expiry date notification

Compare Prices

Figure 5 Reports.

\section{Today's inventory quick inventory}

The total amount of the Search on Items is displayed on top of the page. The lists can be exported and printed (Figure 6).
Quick inventory is used for example when you want to get at a glance the number of implants you have in stock without going around in the drawers to count them.

\section{Quick Inventory (AED 3,150.00)}

Figure 6 Quick inventory.

\section{Dynamic inventory report}

The Dynamic Inventory Report allows monitoring the value of the inventory over 24 months. The amounts are calculated at the end of each month and the charts and lines allow you evaluating the trend (Figure 7). 


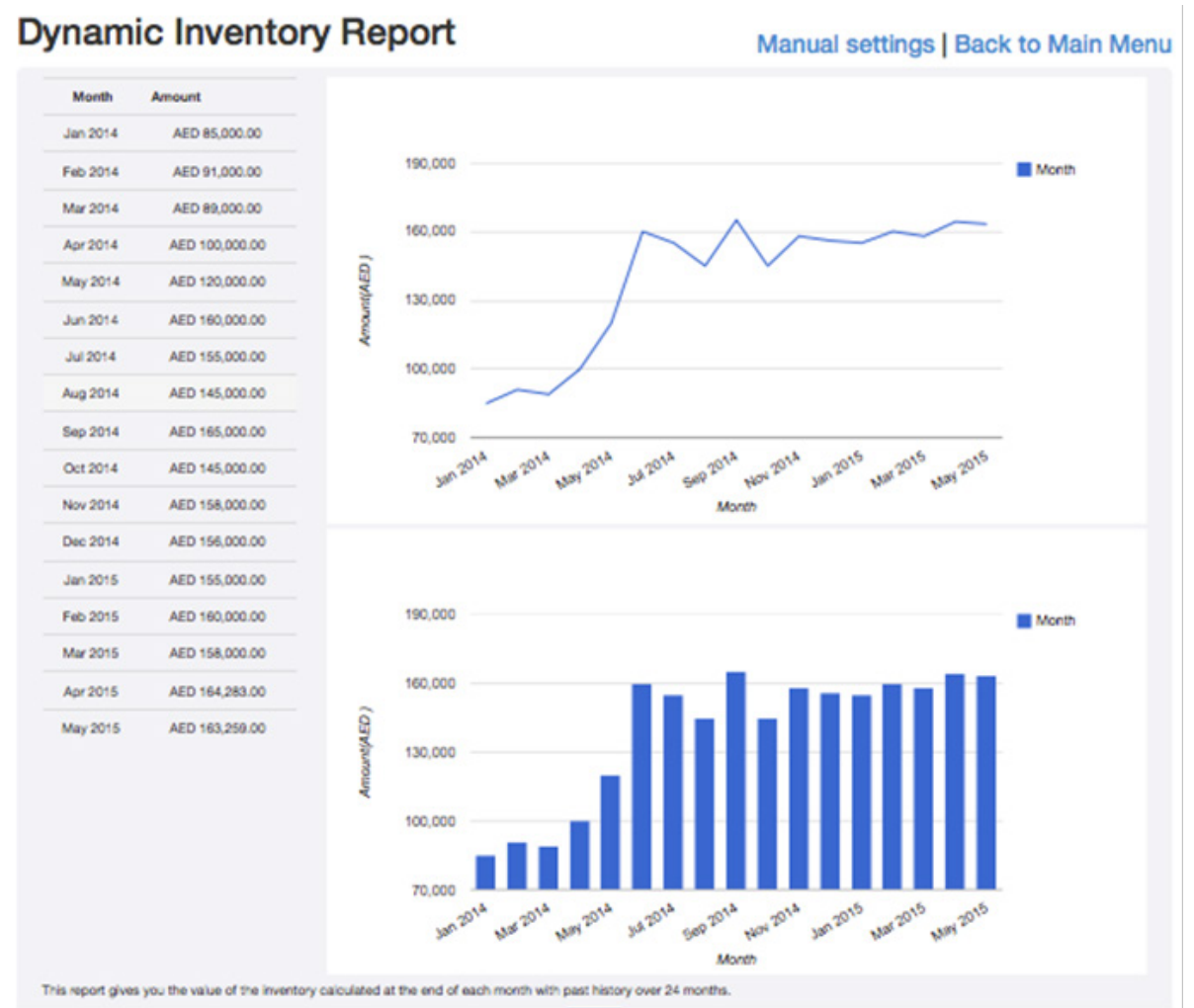

Figure 7 Dynamic inventory report.

\section{Compare prices}

This allows comparing the prices of a same Item sold by different distributors.

\section{One month expiry date notification}

This report gives the list of expired Items and Items on the way to expire in less than one month (Figure 8). This report allows taking the decision to re-order some Items or to use them fast before the expiry date.

\section{One month Expiry date notification}

Back to Main Menu

\begin{tabular}{|c|c|c|c|c|c|}
\hline \multirow{2}{*}{$\begin{array}{l}\text { Item If } \\
\text { Syringe 10mil }\end{array}$} & \multirow{2}{*}{$\begin{array}{l}\text { Location If } \\
\text { Dontal Chat Mobile } \\
\text { cabines }\end{array}$} & \multirow{2}{*}{$\begin{array}{l}\text { Traceability No If } \\
\text { 1010seje2 }\end{array}$} & \multirow{2}{*}{$\begin{array}{l}\text { Status it } \\
\text { nuse }\end{array}$} & \multicolumn{2}{|c|}{ Exply Doto if } \\
\hline & & & & 280022014 & (3) \\
\hline Composite Fitiek a Normal & Ohee closere & & nuse & 300012014 & GO \\
\hline Aoot candulimgation Gyde Syringe ket. & Ohloe closere & & nuso & 31/102014 & 30 \\
\hline Vasedine lquid (hat tonic) & $\begin{array}{l}\text { Dontal Char Fives } \\
\text { Cabinot }\end{array}$ & & nuno & $3011 / 2014$ & 30 \\
\hline Hydrothoric acid Parcelin Esch & Ohloe closere & & in stock & $3011 / 2014$ & (3) \\
\hline Hydrothucic asid Porcoeln Elech & Ohoe oloner & & in stock & $30 / 112014$ & GO \\
\hline Hydrotowaric acid Parceelin Elach & $\begin{array}{l}\text { Dental Chat Fixes } \\
\text { Cabinet }\end{array}$ & & nuse & $30 / 112014$ & (3) \\
\hline ropicale xena & $\begin{array}{l}\text { Dental Chat Frosed } \\
\text { Cabinet }\end{array}$ & 39000 & nuse & 3000/2015 & (3) \\
\hline Tuboul puty poomit Pruty Lab sllicon imoression & Stentizarion Clovet & 167100 & num & 30002015 & (3) \\
\hline Temporary Coment Telo CS ink & Aetroerasose & & nuse & 3000/2015 & 30 \\
\hline Nutosi paste cataynt & Stenilization Closet & 169991 & nuso & $31 / 052015$ & G० \\
\hline Proxn Paste Recla ROA 7 - She (155m) & Othes closere & & in Stock & 30062015 & 30 \\
\hline \multirow[t]{2}{*}{ Select tayout } & \multicolumn{2}{|c|}{ Expred in-stock thems } & & & $\cdot \dot{3}$ \\
\hline & \multicolumn{2}{|c|}{ Pint Exprod h-use Ears } & & & \\
\hline
\end{tabular}

Figure 8 One month expiry date notification. 
Customized report (Orange) (Figure 9)

Customized Reports

Analytic Consumption Report

Export paid invoices to accountancy

Figure 9 Customized report.

\section{Analytic consumption report}

Analytic Consumption Report allows monitoring your consumption based on several search criteria: by category, by distributor, by item, by location, by status, by period, etc (Figure 10).

\section{Export paid invoices to accountancy}

This report allows sending all details about invoices, payments to the accountancy in one time.

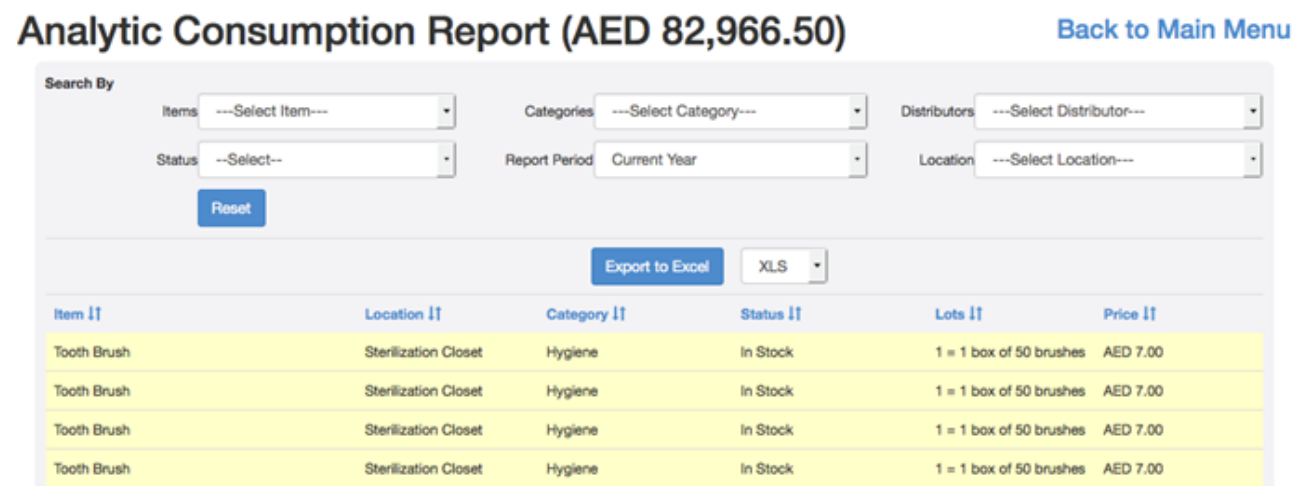

Figure 10 Analytic consumption report

\section{Settings (in Green) (Figure I I)}

Items

a. You can import a list of new Items in one time. The import will come from a CSV or a XLS file (Figure 12). b. You can add a picture in Item's fields.

To easily find pictures to add in your Items details, just go to Google Images and search for the name of your Item. You will then be able to make a screen shot of your picture and import it in your Items details (Figure 13).
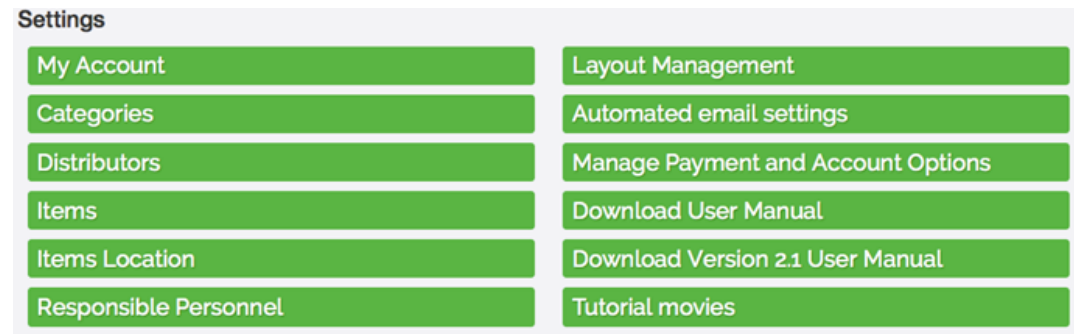

Figure I I Settings.

\section{Select fields to link}

Items | Back to Main Menu

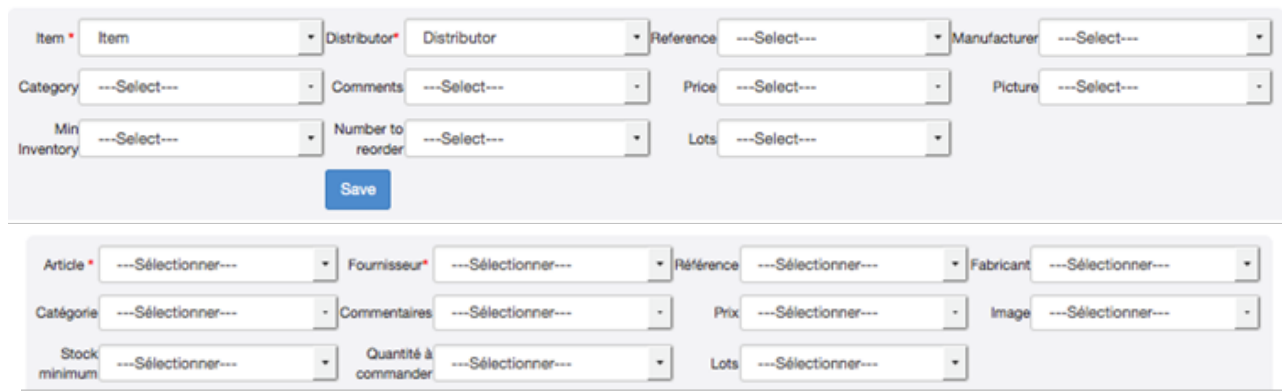

Figure 12 Select fields to link. 


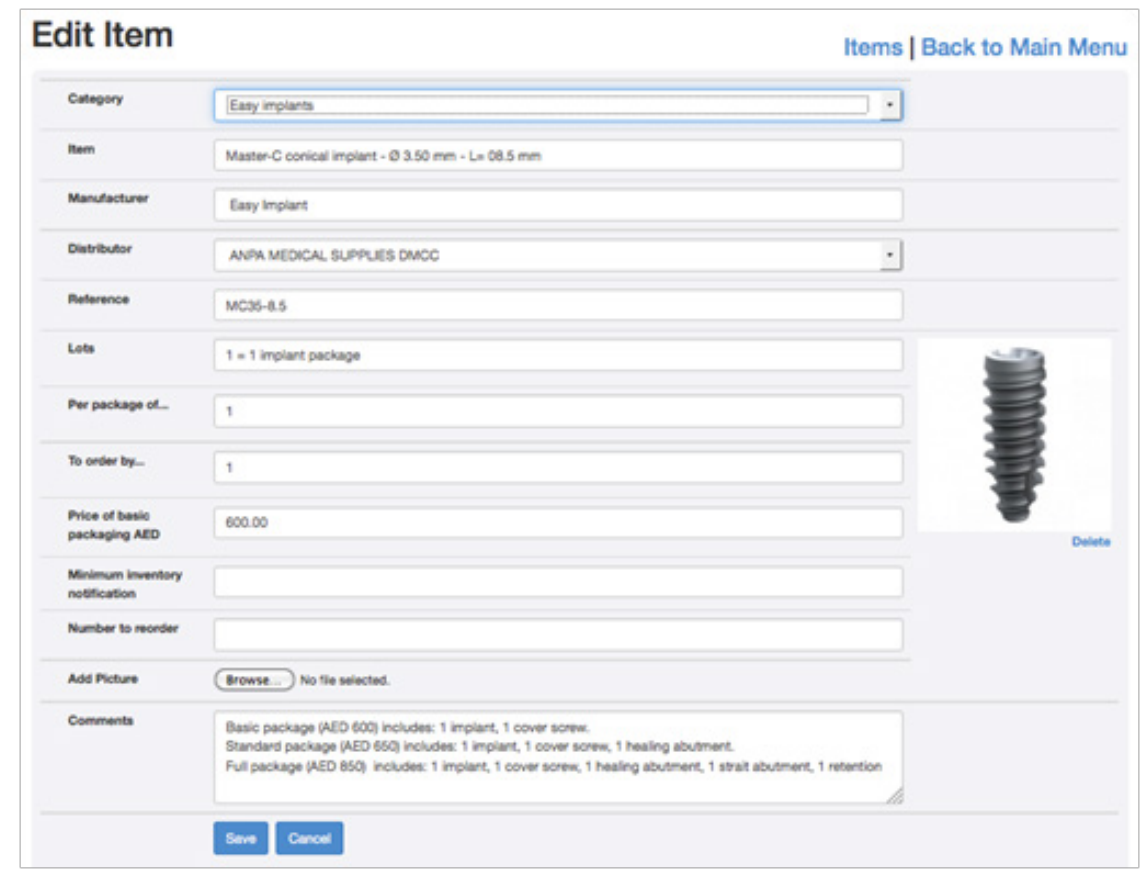

Figure 13 Edit item.

c. Lots, Basic packaging and Minimum quantity to order make things easy to implement (Figure 14). Minimum Inventory Notification and Number to Re-order allows you to be warn before you find that you have no more Items in stock (Figure $15)$.

\begin{tabular}{|l|l|}
\hline Lots & $1=$ box of gloves \\
\hline $\begin{array}{l}\text { Per package } \\
\text { of... }\end{array}$ & 100 \\
\hline \begin{tabular}{l} 
To order by... \\
\hline
\end{tabular} & 1 \\
\hline
\end{tabular}

Figure I 4 Easy to implement.

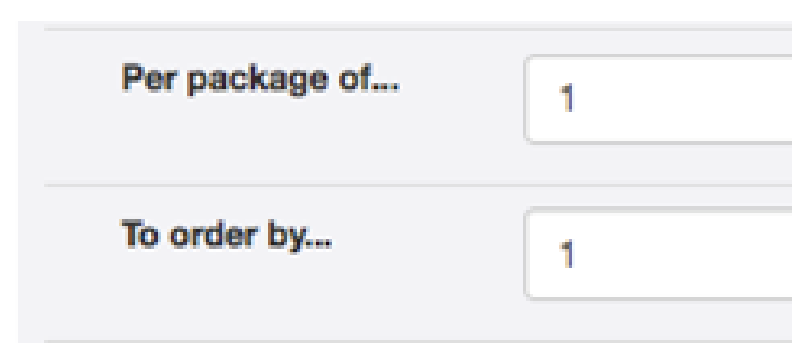

Figure 15 No stock.

\section{Automated email settings}

This page allows you automatically select your reports when you want to receive by e-mail (Figure 16).
In this case, a new line will be automatically opened in Planning Orders. It will be present until your Items will be identified as Received.

Automated email settings

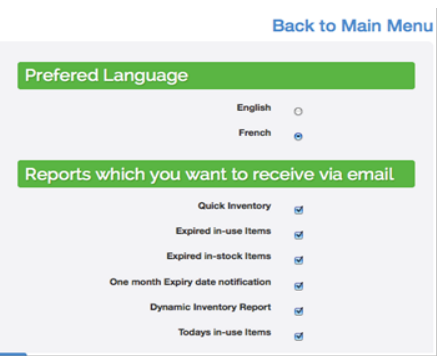

Figure 16 Automated email setting.

Items location (Figure I7)

Items Location (4)

Add New / Back to Main Menu

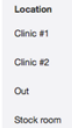

Figure 17 Items location.

Most of users use the Location by room. This allows making analytic search by room (or practitioner) activity in Analytic Consumption report.

\section{Conclusion}

This new online software created by dentists for dentists is answering the problems related to order and stock management specific to medical practices. 
All the tools are accessible online and the intuitive way to work with it allows a very fast and easy implementation whatever size is the dental practice.

All users of this program have been surprised by the amount of money stuck in inventory. Based on this information, users have been able to modify their protocol of decision to order itemsi in a better way.

It is a real satisfaction to get access information in one click. Substantial savings have been done on expenses by all users.

Full version access to Easy Stock-in is available on the web site of ANPA MEDICAL SUPPLIES DMCC. ${ }^{2}$

\footnotetext{
${ }^{2}$ ANPA MEDICAL SUPPLIES DMCC, Dubai, UAE www.anpamedical.com
}

\section{Funding}

None.

\section{Acknowledgements}

None.

\section{Conflicts of interest}

Author declares that there is no conflict of interest. 